\title{
The brain connection between stress and heart: a convincing research opportunity to reduce risk and gender disparity in cardiovascular disease
}

\author{
Roberto Sciagrà, ${ }^{\mathrm{a}}$ Anna Lisa Martini, ${ }^{\mathrm{a}}$ and Michela Allocca ${ }^{\mathrm{a}}$ \\ a Nuclear Medicine Unit, Department of Experimental and Clinical Biomedical Sciences "Mario \\ Serio", University of Florence, Florence, Italy
}

Received Feb 11, 2021; accepted Feb 11, 2021

doi: $10.1007 / \mathrm{s} 12350-021-02583-0$

\section{See related article, pp. 427-432}

The influence of stress on cardiovascular disease is an accepted fact. ${ }^{1-3}$ Several studies have demonstrated that the various forms of psychosocial distress can adversely influence patients with cardiovascular disease. $^{4-7}$ More difficult is to identify the involved mechanisms and even more difficult is to translate this knowledge in treatments or in behavioral changes aimed at reducing or eliminating these adverse effects. ${ }^{2}$

Starting from the studies on the complex pathways involved in the reception of stress by our brain, various groups have addressed the amygdala as important node of the salience network, implicated in the transfer of stressful stimulations on the cardiovascular system by means of sympathetic or neuroendocrine connections, such as the hypothalamic-pituitary-adrenal axis. ${ }^{8-13}$ In particular, higher levels of stress have been shown to produce an increase in amygdalar activity detected by $\left[{ }^{18} \mathrm{~F}\right]$-Fluorodeoxyglucose $\left(\left[{ }^{18} \mathrm{~F}\right] \mathrm{FDG}\right)$ Positron Emission Tomography (PET) imaging. ${ }^{13-16}$ In turn, this augmented activity seems related to various adverse mechanisms, which have unfavorable prognostic effects, such as proinflammatory changes, the occurrence of diabetes, and visceral adiposity. ${ }^{13-15}$

On the other hand, gender differences have emerged both with regard to the relationship between stress and cardiovascular disease and to the presence of brain

\footnotetext{
Reprint requests: Roberto Sciagrà, Nuclear Medicine Unit, Department of Experimental and Clinical Biomedical Sciences "Mario Serio", University of Florence, Florence, Italy; r.sciagra@dfc.unifi.it J Nucl Cardiol 2021;28:433-5.

$1071-3581 / \$ 34.00$

Copyright (C) 2021 American Society of Nuclear Cardiology.
}

changes involved in the cardiovascular response to stress. ${ }^{17-21}$ This requires that the baseline status to be used as reference for stress-induced changes in the involved areas must be established taking into account both age and sex.

In the present issue of the JNC, Haider et al have examined a cohort of patients submitted to $\left[{ }^{18} \mathrm{~F}\right] \mathrm{FDG}$ PET for oncologic indications, after having excluded the presence of clinical cardiovascular disease. ${ }^{22}$ The Authors have measured the amygdalar activity to establish the range of normal values and whether age or sex have any influence on them. They have demonstrated that amygdalar activity in men decreases with age, while in women, no age-related changes have been observed. $^{22}$

The Authors belong to a group that has already intensively addressed the issue of the potential implications of amygdalar activity as a marker of prognosis in patients with cardiovascular disease. ${ }^{16,21}$ Thus, there can be no doubts about the robustness of the provided results and about their reliability. The main problem is that of their usefulness. The Authors conclude that the sex-dependent changes in amygdalar activity must be taken into account when using this metrics as a risk stratification tool for patients with suspected cardiovascular disease. $^{22}$ But is it a reasonable clinical scenario? Probably not, because there are currently several grounds that make this hardly feasible. First of all, in patients with ischemic heart disease, the execution of $\left[{ }^{18} \mathrm{~F}\right] \mathrm{FDG}$ PET for amygdalar activity assessment is completely out of the standard of care, since $\left[{ }^{18} \mathrm{~F}\right] \mathrm{FDG}$ PET is rarely if ever performed for cardiac indications, with the sole of exceptions of few viability studies, valvular or device infection detection or assessment of possible cardiac involvement in sarcoidosis, all circumstances in which the additional value of amygdalar activity measurement would be almost negligible. Given the pressure on PET facilities for performing 
oncological studies, it is very unlikely to foresee an additional use of dedicated $\left[{ }^{18} \mathrm{~F}\right] \mathrm{FDG}$ PET examinations for prognostic purposes, even if it is limited to brain imaging, since the available slots for cardiac PET are already badly needed for myocardial perfusion studies. ${ }^{23}$ So far, the studied cohorts have mainly been selected among oncologic patients. The routine additional assessment of amygdalar activity in these subjects, under the assumption that many of them are as well affected by cardiovascular disease, could be considered, but technical and logistic issues, together with the lacking demonstration of true clinical advantages, make this option unrealistic.

So, what could be the usefulness of the present study? Indeed, what is apparent, looking at the literature on the relationship between brain and cardiovascular disease, it is the difficulty to establish the criteria to assess the efficacy of all possible improvements of psychosocial conditions that should prevent the unfavorable effects of stress. ${ }^{1-3}$ Epidemiological studies aimed at this are by definition difficult to plan, expensive, and require prolonged follow-up on large populations. ${ }^{2}$ In this regard, the availability of reliable surrogate endpoints to establish the baseline degree of psychosocial distress and subsequently the possible treatment-related improvements would be of the utmost value. Although the role of amygdalar activation is by no means definitely clarified, the converging evidence that put this structure in the middle of the stress-related network that connects brain to the cardiovascular system could support the use of amygdalar activity measurement. ${ }^{8-16}$ For this aim, the study by Haider et al helps defining the normality range on which the presence and the regression of pathologic changes must be assessed. ${ }^{22}$

As an additional remark, the different behavior of amygdalar activity according to sex reinforces the notion that women present with a quite different pattern of cardiovascular disease than men, with higher prevalence of non-obstructive causes of ischemia and of stress-related stimulations. ${ }^{19,20}$ The large amount of data that confirms this, from the higher incidence of stress (Takotsubo) cardiomyopathy in women to the higher rate of ischemic responses to mental stress in female patients, to the recent demonstration of a significant increase in events according to higher psychosocial distress in women but not in men, encourages to focus with particular attention to this side of cardiovascular disease in women. ${ }^{7,24-28}$ Hopefully, the further clarification of this higher susceptibility to psychosocial stress could be helpful to improve the treatment of ischemic heart disease in women. Several data suggest that women are as well more sensible to the biological changes that stress induces, and not just to the stressinduced worsening of potentially harmful behaviors. ${ }^{17}$
In this regard, markers of stress-related changes such as amygdalar activity could be extremely important. Particularly, for this critical aim of improving women health, further studies on the stress-related relationships between brain and cardiovascular system, facilitated by the reference data offered by the present study, are highly desirable.

\section{References}

1. Rozanski A, Blumenthal JA, Kaplan J. Impact of psychological factors on the pathogenesis of cardiovascular disease and implications for therapy. Circulation. 1999;99:2192-217.

2. Rozanski A, Blumenthal JA, Davidson KW, Saab PG, Kubzansky L. The epidemiology, pathophysiology, and management of psychosocial risk factors in cardiac practice: the emerging field of behavioral cardiology. J Am Coll Cardiol. 2005;45:637-51.

3. Dar T, Radfar A, Abohashem S, Pitman RK, Tawakol A, Osborne MT. Psychosocial stress and cardiovascular disease. Curr Treat Options Cardiovasc Med. 2019;21:23.

4. Sheps DS, McMahon RP, Becker L, Carney RM, Freedland KE, Cohen JD, et al. Mental stress-induced ischemia and all-cause mortality in patients with coronary artery disease: results from the Psychophysiological Investigations of Myocardial Ischemia study. Circulation. 2002;105:1780-4.

5. Rosengren A, Hawken S, Ounpuu S, Sliwa K, Zubaid M, Almahmeed WA, et al. Association of psychosocial risk factors with risk of acute myocardial infarction in 11119 cases and 13648 controls from 52 countries (the INTERHEART study): case-control study. Lancet. 2004;364:953-62.

6. Stewart RAH, Colquhoun DM, Marschner SL, Kirby AC, Simes J, Nestel PJ, et al. Persistent psychological distress and mortality in patients with stable coronary artery disease. Heart. 2017;103:1860-6.

7. Pimple P, Lima BB, Hammadah M, Wilmot K, Ramadan R, Levantsevych $\mathrm{O}$, et al. Psychological distress and subsequent cardiovascular events in individuals with coronary artery disease. J Am Heart Assoc. 2019;8:e011866.

8. Phelps EA, LeDoux JE. Contributions of the amygdala to emotion processing: from animal models to human behavior. Neuron. 2005;48:175-87

9. Ginty AT, Kraynak TE, Fisher JP, Gianaros PJ. Cardiovascular and autonomic reactivity to psychological stress: Neurophysiological substrates and links to cardiovascular disease. Auton Neurosci. 2017;207:2-9.

10. Tawakol A, Osborne MT, Wang Y, Hammed B, Tung B, Patrich $\mathrm{T}$, et al. Stress-associated neurobiological pathway linking socioeconomic disparities to cardiovascular disease. J Am Coll Cardiol. 2019;73:3243-55.

11. Fonseca R, Madeira N, Simoes C. Resilience to fear: The role of individual factors in amygdala response to stressors. Mol Cell Neurosci. 2021;110:103582.

12. Wager TDC, Waugh CE, Lindquist M, Noll DC, Fredrickson BL, Taylor SF. Brain mediators of cardiovascular responses to social threat: part I: Reciprocal dorsal and ventral sub-regions of the medial prefrontal cortex and heart-rate reactivity. Neuroimage. 2009;47:821-35.

13. Ishai A, Osborne MT, Tung B, Wang Y, Hammad B, Patrich T, et al. Amygdalar metabolic activity independently associates with progression of visceral adiposity. J Clin Endocrinol Metab. 2019;104:1029-38. 
14. Tawakol A, Ishai A, Takx RA, Figueroa AL, Ali A, Kaiser Y, et al. Relation between resting amygdalar activity and cardiovascular events: a longitudinal and cohort study. Lancet. 2017;389:834-45.

15. Osborne MT, Ishai A, Hammad B, Tung B, Wang Y, Baruch A, et al. Amygdalar activity predicts future incident diabetes independently of adiposity. Psychoneuroendocrinology. 2018;100:3240

16. Fiechter M, Roggo R, Burger IA, Bengs S, Treyer V, Becker A, et al. Association between resting amygdalar activity and abnormal cardiac function in women and men: a retrospective cohort study. Eur Heart J Cardiovasc Imaging. 2019;20:625-32.

17. Orth-Gomér K, Wamala SP, Horsten M, Schenck-Gustafsson K, Scheiderman N, Mittleman MA. Marital stress worsens prognosis in women with coronary heart disease: the Stockholm Female Coronary Risk Study. JAMA. 2000;284:3008-14.

18. Kubzansky LD, Koenen KC, Jones C, Eaton WW. A prospective study of posttraumatic stress disorder symptoms and coronary heart disease in women. Health Psychol. 2009;28:125-30.

19. Wenger NK. Clinical presentation of CAD and myocardial ischemia in women. J Nucl Cardiol. 2016;23:976-85.

20. Waheed N, Elias-Smale S, Malas W, Maas AH, Sedlak TL, Tremmel J, et al. Sex differences in non-obstructive coronary artery disease. Cardiovasc Res. 2020;116:829-40.

21. Fiechter M, Haider A, Bengs S, Marędziak M, Burger IA, Roggo A, et al. Sex-dependent association between inflammation, neural stress responses, and impaired myocardial function. Eur J Nucl Med Mol Imaging. 2020;47:2010-5.

22. Haider A, Bengs S, Diggelmann F, Epprecht G, Etter D, Beeler $\mathrm{AL}$, et al. Age- and sex-dependent changes of resting amygdalar activity in individuals free of clinical cardiovascular disease. $\mathbf{J}$ Nucl Cardiol. 2021 Jan 13. https://doi.org/10.1007/s12350-020-0 2504-7.
23. Sciagrà R, Passeri A, Bucerius J, Verberne HJ, Slart RH, Lindner $\mathrm{O}$, et al. Cardiovascular Committee of the European Association of Nuclear Medicine (EANM)X Clinical use of quantitative cardiac perfusion PET: rationale, modalities and possible indicationsX Position paper of the Cardiovascular Committee of the European Association of Nuclear Medicine (EANM). Eur J Nucl Med Mol Imaging. 2016;43:1530-45.

24. Bremner JD, Vermetten E, Schmahl C, Vaccarino V, Vythilingam $\mathrm{M}$, Afzal N, et al. Positron emission tomographic imaging of neural correlates of a fear acquisition and extinction paradigm in women with childhood sexual-abuse-related post-traumatic stress disorder. Psychol Med. 2005;35:791-806.

25. Templin C, Ghadri JR, Diekmann J, Napp LC, Bataiosu DR, Jaguszewski M, et al. Clinical features and outcomes of takotsubo (stress) cardiomyopathy. N Engl J Med. 2015;373:929-38.

26. Pimple P, Hammadah M, Wilmot K, Ramadan R, Al Mheid I, Levantsevych $\mathrm{O}$, et al. Chest pain and mental stress-induced myocardial ischemia: sex differences. Am J Med. 2018;131(540547):e1.

27. Vaccarino V, Sullivan S, Hammadah M, Wilmot K, Al Mheid I, Ramadan R, et al. Mental stress-induced-myocardial ischemia in young patients with recent myocardial infarction: Sex differences and mechanisms. Circulation. 2018;137:794-805.

28. Vaccarino V, Wilmot K, Al Mheid I, Ramadan R, Pimple P, Shah $\mathrm{AJ}$, et al. Sex differences in mental stress-induced myocardial ischemia in patients with coronary heart disease. J Am Heart Assoc. 2016;5:e003630.

Publisher's Note Springer Nature remains neutral with regard to jurisdictional claims in published maps and institutional affiliations. 